\title{
Photoperiodic regulation of glutamatergic stimulation of secretion of luteinizing hormone in male Syrian hamsters
}

\author{
Y. Hui, M. H. Hastings, E. S. Maywood and F. J. P. Ebling* \\ Department of Anatomy, University of Cambridge, $U K$
}

\begin{abstract}
Summary. It has been suggested that changes in endogenous glutamatergic stimulation of secretion of luteinizing hormone $(\mathrm{LH})$ induced by photoperiod play a role in regulating seasonal cycles of reproductive activity. The aim of this study was to test the hypothesis that the glutamatergic control of the secretion of LH in the male Syrian hamster is sensitive to photoperiod, by determining whether the glutamate agonist $N$ methyl-D-aspartate (NMDA) could stimulate LH secretion in this species and, if so, to determine whether the response varied among animals exposed to different daylengths. In the first experiment, adult male hamsters were housed in either short days $(8 \mathrm{~h} \mathrm{light:}$ $16 \mathrm{~h}$ dark) for 6 weeks to induce testicular regression, or long days ( $16 \mathrm{~h}$ light: $8 \mathrm{~h}$ dark) to maintain testicular function, and the effects of systemic administration of NMDA on serum LH concentrations were determined. In the short-day hamsters, all s.c. doses of NMDA (25-75 $\mathrm{mg} \mathrm{kg}^{-1}$ body weight) produced a robust rise in serum LH concentrations within $15 \mathrm{~min}$. In the long-day hamsters, basal LH concentrations were higher than in short-day hamsters, but only the highest dose of NMDA produced a significant increase in LH concentrations, and the magnitude of this increment was less than those observed in short days. In hamsters in long days, the low doses of NMDA that did not significantly alter LH concentrations nevertheless significantly suppressed serum prolactin concentrations, demonstrating the efficacy of the drug. In hamsters in short days, serum prolactin concentrations were at the limit of detection of the assay, so no inhibitory effect of NMDA on prolactin secretion could be determined on this photoperiod. In the second experiment, the effects of a fixed dose of NMDA $\left(50 \mathrm{mg} \mathrm{kg} \mathrm{k}^{-1}\right.$ body weight) was tested at intervals in hamsters exposed to short days for a prolonged period such that their testes initially regressed, but then became scotorefractory and testicular recrudescence occurred. After 6 and 12 weeks in short days, NMDA stimulated LH secretion. However, after 24 weeks in short days when testicular recrudescence was complete, the response to NMDA was lost. A third experiment determined whether the reduced response to NMDA in hamsters on long days relative to those in short days might result from higher concentrations of circulating testosterone. Hamsters in long days were castrated to remove the influence of gonadal feedback, and the response to NMDA tested 3 weeks later when endogenous LH concentrations had risen to levels characteristic of the chronically castrated condition. NMDA significantly reduced serum $\mathrm{LH}$ in castrated hamsters. Thus, the increased $\mathrm{LH}$ response to NMDA in hamsters in short days is unlikely to reflect the very low serum testosterone concentrations at this time. A preliminary experiment was conducted with the glutamate antagonist MK801 to investigate whether endogenous glutamatergic mechanisms support LH secretion in hamsters in long days. Systemic treatment with MK801 $\left(0.6 \mathrm{mg} \mathrm{kg}^{-1}\right.$ body weight, i.p.) did not significantly alter $\mathrm{LH}$ concentrations at 30 or 60 min after injection, though this dose did increase LH secretion in castrate hamsters
\end{abstract}

${ }^{*}$ Corresponding author. 
as might be expected in view of the paradoxical inhibitory action of NMDA in castrates. Although this acute experimental paradigm did not provide direct evidence for endogenous glutamatergic control of LH in sexually active hamsters, the increased sensitivity and responsiveness to the agonist NMDA in hamsters in short days is consistent with the view that endogenous glutamatergic stimulation is decreased in this photoperiod, and that this decreased activity contributes to the regression of the reproductive axis.

Keywords: photoperiod; NMDA; LH; prolactin; hamster; season

\section{Introduction}

The changes in gonadotrophin secretion that underlie annual cycles in testicular function in seasonally breeding mammals are likely to reflect altered secretion of gonadotrophin-releasing hormone (GnRH) by the hypothalamus (Ebling \& Foster, 1990). The pattern of melatonin secretion from the pineal gland mediates the effects of changing photoperiod on neuroendocrine function, but the chemical identity and location of neuronal systems that respond to melatonin and regulate $\mathrm{GnRH}$ secretion are not known (Hastings et al., 1991). Many studies have examined the possibility that increased activity of inhibitory pathways decreases GnRH secretion in the non-breeding season. For example, the role of endogenous opioid and catecholamine pathways has been studied by testing the effect of receptor antagonists on luteinizing hormone (LH) secretion (Ebling \& Lincoln, 1985; Meyer \& Goodman, 1985; Roberts et al., 1985; Juss et al., 1991). An alternative, and probably complementary, hypothesis is that the increased GnRH secretion that induces the breeding season reflects the activation of stimulatory neurochemical mechanisms. In support of this hypothesis, several studies have demonstrated that $N$-methyl-D-aspartate (NMDA), an agonist for the excitatory amino acid neurotransmitter glutamate, can stimulate $\mathbf{L H}$ secretion. These effects of NMDA are most prominent in hypogonadotrophic conditions such as the prepubertal period in the rhesus monkey and rat (Gay \& Plant, 1987; Urbanski \& Ojeda, 1987), and during dietaryinduced delayed puberty in sheep (Ebling et al., 1990). Moreover, repeated administration of this agonist sustains LH secretion in prepubertal sheep and monkeys (Ebling et al., 1990; Gay \& Plant, 1988), and can result in premature gonadal activation in prepubertal male rhesus monkeys and female rats (Plant et al., 1989; Urbanski \& Ojeda, 1987). Collectively, these studies indicate the potential for hypogonadotrophic mammals to be stimulated by glutamatergic mechanisms, and support the hypothesis that environmentally or developmentally dependent hypogonadism is a consequence of inadequate glutamatergic activation of $\mathrm{GnRH}$ secretion. The observations that NMDA receptor antagonists can block the mid-cycle steroid-induced LH surge (Urbanski \& Ojeda, 1990; Lopez et al., 1990; Brann \& Mahesh, 1991a,b), and delay the timing of puberty (Urbanski \& Ojeda, 1990; Veneroni et al., 1990; Wu et al., 1990) provide direct evidence that endogenous glutamatergic pathways play a role in the physiological control of GnRH secretion.

The period of sexual quiescence in a seasonal breeder resembles the prepubertal period in some respects (Ebling \& Foster, 1990). The principal aim of the current study was therefore to investigate whether the potential exists for glutamate regulation of LH secretion during the inactive phases of the reproductive cycle in a seasonally breeding rodent, the Syrian hamster, and to determine whether NMDA stimulation varies across the photoperiodically driven reproductive cycle. Such an observation might provide an indication of changing activity of endogenous glutamatergic mechanisms. The effects of glutamate agonists on prolactin secretion were also examined to provide a second measure of neuroendocrine responsiveness to the drug, and also because changing prolactin secretion itself may contribute to the seasonal cycle in testicular function in this species (Bartke et al., 1980). Parts of this study were presented as a preliminary communication (Hui et al., 1991). 


\section{Materials and Methods}

\section{General}

Adult male Syrian hamsters (Wrights, Essex) were individually housed with water and lab chow available ad libitum. The room was lit by twin 6 foot, $70 \mathrm{~W}$ fluorescent white strips, and a single red tube was on continuously

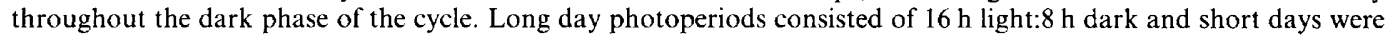
$8 \mathrm{~h}$ light: $16 \mathrm{~h}$ dark (lights on $07: 00 \mathrm{~h}$ ). Blood samples were collected by cardiac puncture under light ether anaesthesia during the light phase of the photoschedule. Samples were allowed to clot at room temperature overnight, centrifuged and serum was removed and stored at $-20^{\circ} \mathrm{C}$ until radioimmunoassay.

\section{Radioimmunoassays}

Serum LH concentrations were measured using a rat LH kit provided by the NIADDK, using preparation RP-3 as the standard. Samples were assayed in duplicate in eight assays; mean limit of detection was $0.02 \mathrm{ng}$ per tube $\left(=0.2 \mathrm{ng} \mathrm{ml}^{-1}\right.$ when using $100 \mu \mathrm{l}$ serum). Mean estimates of intra- and interassay CVs on the basis of duplicate quality control sera run in all assays were $5 \cdot 8 \%$ and $22 \cdot 1 \%$, respectively. Prolactin concentrations were determined in a homologous radioimmunoassay using an antiserum against hamster prolactin provided by $F$. Talamantes (Talamantes et al., 1984), and purified hamster prolactin iodinated tracer and standard preparation from the NIADDK kit provided by A. F. Parlow (Harbor-UCLA, CA, U.S.A.). Samples were assayed in duplicate in four assays; mean limit of detection was $0.08 \mathrm{ng}$ per tube ( $=4 \mathrm{ng} \mathrm{ml}^{-1}$ when using $20 \mu \mathrm{l} \mathrm{serum}$ ). Intra- and interassay CVs (estimated as above) were $6.4 \%$ and $11.0 \%$, respectively.

\section{Drugs}

$N$-methyl-D,L-aspartate was purchased from Sigma (Poole, UK) as the racemic mixture; concentrations are expressed as those of the active D isomer, hence the abbreviation NMDA. MK80I was a gift from S. Iversen (Merck, Sharp and Dohme Neuroscience Research Centre, Harlow, UK). Both drugs were dissolved in sterile $0.01 \mathrm{~mol}$ phosphate-buffered saline $\mathrm{l}^{-1}$, and $\mathrm{pH}$ was adjusted to neutral before injection. Hamsters were weighed before each experiment.

\section{Treatments}

Experiment 1: Effects of NMDA on LH and prolactin secretion in reproductively quiescent and in reproductively active hamsters. Adult male Syrian hamsters were kept in short days for 6 weeks at which time the testes were palpated to ensure that testicular regression had occurred. Groups of seven to nine hamsters received s.c. injections of vehicle $\left(0.01 \mathrm{~mol}\right.$ PBS $\left.\mathrm{l}^{-1}\right)$ or NMDA at 25,50 or $75 \mathrm{mg} \mathrm{kg}^{-1}$ body weight and a blood sample taken 15 min later.

Several treatments were carried out in reproductively active hamsters maintained in long days. First, hamsters were injected subcutaneously with vehicle $\left(0.01 \mathrm{~mol} \mathrm{PBS}^{-1}\right)$ or NMDA at $25,50 \mathrm{or} 75 \mathrm{mg} \mathrm{kg}^{-1}$ body weight, and blood samples were collected $15 \mathrm{~min}$ later for measurement of $\mathrm{LH}$ and prolactin. Second, groups of long-day hamsters received vehicle or $12.5,25,50,80$ or $100 \mathrm{mg} \mathrm{NMDA} \mathrm{kg}^{-1}$ body weight as i.p. injections to determine whether the route of administration altered the efficacy of the drug. Finally, time course studies were conducted in which longday hamsters received vehicle or $50 \mathrm{mg}$ NMDA $\mathrm{kg}^{-1}$ body weight, and blood samples from different groups were collected at 10,15, 20 and 30 min after injection.

Experiment 2: Effects of NMDA on LH and prolactin secretion during a photoperiod-induced cycle in reproductive activity. The hamsters that received vehicle or the $50 \mathrm{mg} \mathrm{NMDA} \mathrm{kg}^{-1}$ body weight in the short-day dose response study were maintained in short days, and were tested with the same treatments after a further 6 weeks in short days (12 weeks total), when their testes were still regressed, as determined by transcrotal palpation, and again after a total of 24 weeks in short days when palpation revealed that full testicular recrudescence had occurred. On each occasion blood samples were collected $15 \mathrm{~min}$ after NMDA or vehicle treatment for measurement of LH and prolactin.

Experiment 3: Effect of castration on the LH response to NMDA and MK801 in long-day hamsters. As a preliminary investigation of whether endogenous glutamatergic mechanisms are necessary for the maintenance of LH secretion in intact sexually active hamsters held in long days, the effects of the noncompetitive NMDA receptor antagonist, MK801, on LH secretion were determined. Four groups of hamsters $(n=7$ or 8 ) were injected i.p. with $0.6 \mathrm{mg}$ MK801 kg-1 body weight or vehicle and blood samples were collected for LH measurements at either 30 or $60 \mathrm{~min}$ after injection from both control and treatment groups. This dose of MK801 was chosen because doses of similar magnitude can block endogenous and steroid-induced LH surges in the rat (Urbanski \& Ojeda, 1990; Brann \& Mahesh, 199la, b). This dose does not induce sedation in hamsters (Ebling et al., 199la). Studies were conducted on castrated hamsters for two reasons. First, it was anticipated that the increased LH concentrations after castration would provide a more sensitive model in which to detect any suppressive effect of glutamate antagonists on $\mathrm{LH}$ secretion (e.g. Arslan et al., 1988). Second, in view of the change in sensitivity to NMDA observed in Expt 1 after 
testicular atrophy (see below), it was necessary to determine whether testicular secretions influenced the effect of NMDA on LH secretion. Hamsters kept in long days $(n=16)$ were castrated under Avertin anaesthesia (tribromoethanol:tertiary amyl alcohol $(2: 1), 1 \mathrm{ml}$ per $100 \mathrm{~g}$ body weight, i.p.). One week after surgery during the expected LH rise after castration (Urbanski \& Simpson, 1982), hamsters were treated with MK801 $\left(0.6 \mathrm{mg} \mathrm{kg}^{-1}\right.$ body weight, i.p.) or vehicle, and blood samples collected $1 \mathrm{~h}$ later. The experiment was repeated 2 weeks after castration when $\mathrm{LH}$ concentrations would be expected to have risen further. Finally, 3 weeks after castration, by which time LH concentrations would be expected to have reached a plateau (Urbanski \& Simpson, 1982), hamsters were treated with 75 mg NMDA kg ${ }^{-1}$ body weight or vehicle s.c., and blood samples collected after 30 min for measurement of LH concentrations. Hamsters were randomly allocated to treatment groups across the 3 weeks to avoid any possible effects related to the sequence of treatment.

\section{Statistical analysis}

Data were analysed by factorial or repeated measures ANOVA as appropriate (Statview, Calabas, CA, USA), followed by Dunnett $t$ tests for comparison of NMDA treatment means with the vehicle means (dose-response experiments) or followed by unpaired $t$ tests to compare vehicle and treatment means at different stages of the photoperiod-induced reproductive cycle. Hormone concentrations falling below the limit of detection were assigned this value for the purposes of statistical analysis and presentation of data.

\section{Results}

\section{Experiment 1: Effects of NMDA on LH and prolactin secretion in reproductively quiescent and reproductively active hamsters}

In animals held in short daylengths, all doses of NMDA tested produced a significant increase in serum $\mathrm{LH}$ over vehicle control concentrations, concentrations were increased approximately fourfold relative to the controls at $15 \mathrm{~min}$ after drug administration (drug effect $F=12 \cdot 2,3$ d.f., $P<0.0001$ ). Serum prolactin concentrations from most reproductively suppressed hamsters were below the limit of detection of the assay and so no differences between vehicle and NMDA-treated groups could be determined. As anticipated, concentrations of LH and prolactin in serum were significantly higher in the vehicle-treated controls held in long days than in those held in short days $(P<0.01)$. ANOVA $(F=7.3,3$ d.f., $P<0.001)$ revealed a significant effect of treatment on LH concentrations, but only in the highest treatment group ( $75 \mathrm{mg} \mathrm{NMDA} \mathrm{kg}{ }^{-1}$ body weight) were concentrations significantly different $(P<0.005)$ from the vehicle controls. The magnitude of the increment over vehicle controls at this NMDA dose was less than twofold. In the long-day hamsters, all NMDA doses significantly decreased serum prolactin concentrations relative to vehicle controls $(F=10 \cdot 1,3$ d.f., $P<0 \cdot 0001)$.

Hamsters were less sensitive to i.p. injection of NMDA than to s.c. injection (Fig. 2). A dose of $80 \mathrm{mg}$ NMDA kg-1 body weight was not effective; a significant effect of NMDA on LH secretion was seen only at a dose of $100 \mathrm{mg}$ NMDA kg-1 body weight $(P<0.01)$. This dose induced behavioural side effects, notably hyperactivity, and hyperventilation, and two animals failed to recover from ether anaesthesia after this dose of NMDA. Further studies using this protocol were therefore terminated.

The time course studies in long-day hamsters failed to show an effect of s.c. injection of $50 \mathrm{mg}$ NMDA kg ${ }^{-1}$ body weight on serum LH concentrations 10,15, 20 or 30 min after injection (data not shown). However, serum prolactin concentrations were significantly $(P<0.05)$ suppressed at both 15 and $30 \mathrm{~min}$ after injection relative to vehicle-treated hamsters sampled $15 \mathrm{~min}$ after injection (vehicle $12.5 \pm 1.6 \mathrm{ng} \mathrm{ml}^{-1}, n=13$; NMDA at $15 \mathrm{~min} 6.2 \pm 0.9 \mathrm{ng} \mathrm{ml}^{-1}, n=14$; NMDA at $30 \mathrm{~min} 4 \cdot 6 \pm 0.4 \mathrm{ng} \mathrm{ml}^{-1}, n=12$ ).

\section{Experiment 2: Effects of NMDA on LH and prolactin secretion during a photoperiod-induced cycle in reproductive activity}

In vehicle-treated hamsters, ANOVA revealed a significant effect $(P<0.01)$ of time on both LH and prolactin values. The concentration of both hormones had decreased by 6 weeks of short-day 


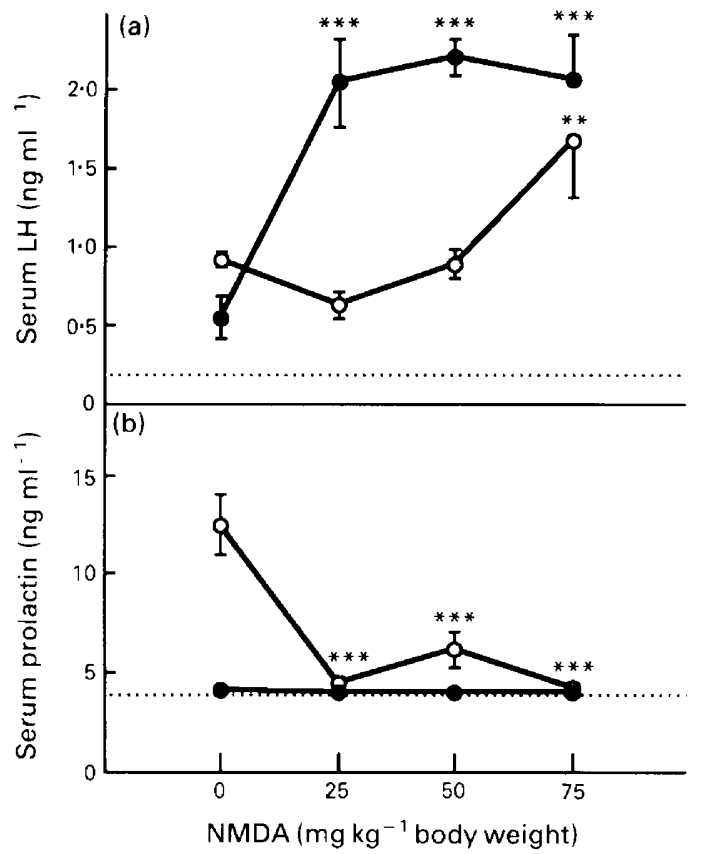

Fig. 1. (a) Serum luteinizing hormone (LH) and (b) serum prolactin concentrations in adult male Syrian hamsters kept in long days $(O)$ or for 6 weeks in short days $(\bullet)$, and treated subcutaneously with vehicle or NMDA $15 \mathrm{~min}$ before sampling. Dotted line indicates mean limit of detection for the radioimmunoassays. Values are means \pm SEM, $n=7-9$ per dose for short-day animals and 1429 per dose for long-day animals. ${ }^{* *} P<0 \cdot 01 ;{ }^{* * *} P<0.001$ versus vehicle control for that photoperiod.

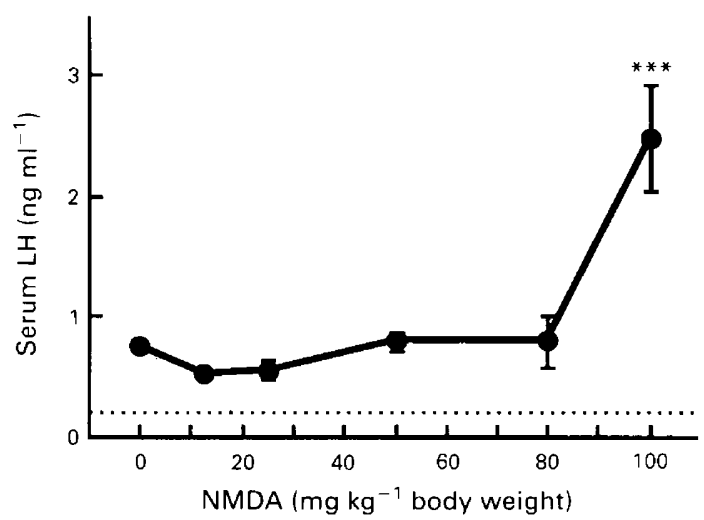

Fig. 2. Serum luteinizing hormone (LH) concentrations in adult male Syrian hamsters kept in long days and treated intraperitoneally with vehicle or NMDA 15 min before sampling. Dotted line indicates mean limit of detection for the radioimmunoassays. Values are means \pm SEMs, $n=6-8$ per dose, ${ }^{* * *} P<0.001$ versus vehicle control.

treatment relative to values from long-day hamsters, and had increased by 24 weeks in short days relative to the levels after 6 and 12 weeks on short days. There was a significant interaction between time and drug treatment for both hormones (ANOVA LH: $F=31 \cdot 2, P<0 \cdot 0001$; prolactin: $F=4 \cdot 0$, $P=0.01$ ). Post hoc $t$ tests revealed that serum LH concentrations were significantly increased by NMDA after 6 and 12 weeks of short-day exposure (Fig. 3), whereas by 24 weeks of short days, 
when the animals were scotorefractory and reproductively active, NMDA had no effect on serum LH. After 24 weeks of short-day exposure, serum prolactin concentrations were significantly $(P<0.05)$ decreased by NMDA, in a manner similar to that seen in hamsters maintained in long days.

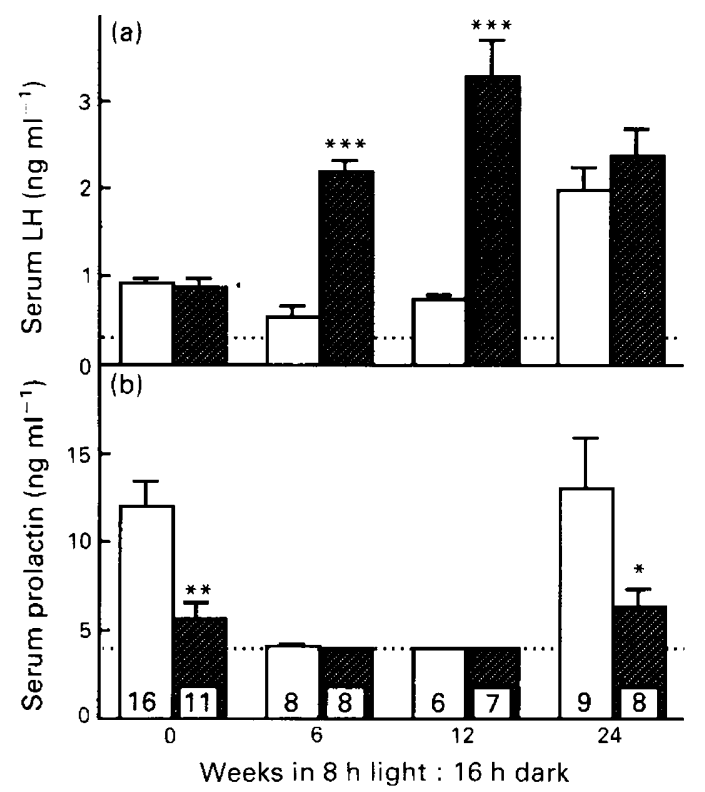

Fig. 3. (a) Serum LH and (b) serum prolactin concentrations in adult male Syrian hamsters kept in short days for the length of time indicated, and treated subcutaneously with vehicle (open bar) or $50 \mathrm{mg}$ NMDA kg-1 body weight (shaded bar) $15 \mathrm{~min}$ before sampling. Dotted line indicates mean limit of detection for the radioimmunoassays. Values are means \pm SEM, group sizes as indicated in the bars. ${ }^{*} P<0.05,{ }^{* *} P<0.01,{ }^{* * *} P<0.001$ versus vehicle control for that time point. Values at week 0 are from a separate group of hamsters tested as above on long days, and are replotted from Fig. 1.

\section{Experiment 3: Effect of castration on the LH response to NMDA and MK801 in long-day hamsters}

In intact, long-day hamsters, the single i.p. dose of MK801 did not significantly alter LH concentrations relative to vehicle-injected controls at either $30 \mathrm{~min}$ after injection (vehicle: $1 \cdot 30 \pm 0 \cdot 20$ versus MK801: $1.62 \pm 0 \cdot 12 \mathrm{ng} \mathrm{ml}^{-1}, n=8$ per group) or 60 min after injection (Fig. 4, left). Castration of long-day hamsters induced the expected increase in LH secretion. In vehicletreated hamsters, serum LH concentrations had increased above intact values by 1 week after castration, and continued to rise at week 2 and 3 (Fig. 4, open bars). Although it was originally anticipated that a glutamate antagonist would decrease $\mathrm{LH}$ concentrations, treatment of castrates with MK801 actually caused a significant $(P<0 \cdot 05)$ increase in LH concentrations $1 \mathrm{~h}$ after injection relative to vehicle-injected controls on both occasions (Fig. 4). Correspondingly, when studied 3 weeks after castration, NMDA treatment induced a marked decrease $(P<0.001)$ in serum LH concentrations at 30 min after injection (Fig. 4, right).

\section{Discussion}

The present study demonstrates that the potential for glutamatergic regulation of the secretion of both $\mathrm{LH}$ and prolactin exists in this species. Furthermore, it was observed that the sensitivity to 


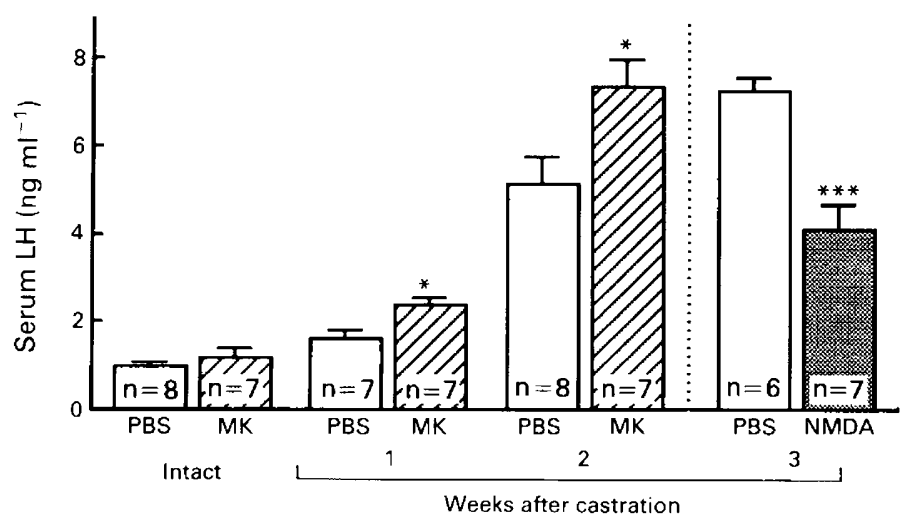

Fig. 4. Summary of various experiments with MK801 (NMDA antagonist) in intact or castrate hamsters. Serum LH concentrations $1 \mathrm{~h}$ after treatment with vehicle (open bar, PBS) or $0.6 \mathrm{mg}$ MK801 kg-1 body weight i.p. (hatched bar, MK) are shown. Effect of vehicle (open bar, PBS) or $75 \mathrm{mg}$ NMDA $\mathrm{g}^{-1}$ body weight s.c. (stippled bar) given $30 \mathrm{~min}$ before blood sampling are shown. Values are means \pm SEMs, group sizes as indicated in the bars. ${ }^{*} P<0.05,{ }^{*} * * P<0.001$ versus vehicle control.

activation by NMDA of the mechanisms controlling $\mathrm{LH}$ release changes across a reproductive cycle induced by photoperiod. The secretion of LH in gonadally active animals held in long days was less sensitive to stimulation by NMDA than in photoinhibited animals exposed to short days for 6 or 12 weeks. In gonadally active animals, doses of NMDA that did not affect serum LH concentrations as assessed on the basis of a single blood sample did, however, suppress the secretion of prolactin. Reactivation of the gonadal axis due to the development of scotorefractoriness after 24 weeks on short days was associated with attenuation of the LH response to NMDA. Similarly, restoration of the long-day-type inhibitory response of prolactin to NMDA administration was also observed in scotorefractory animals. These results demonstrate that the effects of NMDA are determined not by the photoperiod per se, but by the seasonal state of the animal, which is itself synchronized by changes in photoperiod.

Although the current experimental approach is undoubtedly pharmacological in that the high doses of agonist might be expected to induce activation of multiple stimulatory and inhibitory systems within the CNS, the observation that the response to the pharmacological challenge varies in different reproductive states does indicate the usefulness of the approach in revealing underlying changes in physiological state. A second caveat to the experimental design is that $\mathrm{LH}$ secretion is pulsatile in the hamster, as in other species (Swann \& Turek, 1988). Thus, the failure to demonstrate a significant change in LH concentration on the basis of a single blood sample taken after treatment does not necessarily mean that a change in the pattern of LH secretion has not occurred. Changes in the pattern (e.g. frequency) of episodic LH release are probably important in driving alterations in reproductive function (Hastings, 1991), thus studies of the effects of glutamate agonists and antagonists on the pattern of LH secretion are clearly essential. The current results derived from infrequent blood sampling paradigms are, however, in close accord with a recent study in male sheep in which a detailed examination of the effects of NMDA on the episodic pattern of LH secretion was carried out (Lincoln \& Wu, 1991). The latter study demonstrated that in animals exposed to an inhibitory long-day photoperiod with regressing testes, low i.v. doses of NMDA rapidly induced a prolonged period of LH secretion. In contrast, during the phase of testicular recrudescence after exposure to stimulatory short days, sensitivity to NMDA was markedly reduced, and only a transient response could be elicited (Lincoln \& Wu, 1991). 
Urbanski (1990) observed that one i.p. NMDA injection a day could prevent gonadal regression induced by short days in the Syrian hamster, and could also rapidly stimulate testicular recrudescence in hamsters kept in short days. However, no differences in the response to NMDA in long and short photoperiods were detected in the latter study. The reason for such a discrepancy between the current experiments and that of Urbanski may reside in several important differences between the protocols. First, Urbanski (1990) tested only a single dose of NMDA (20 mg kg-1 body weight) on the long and short day photoperiods, and this was given intravenously. Given the more effective access to the brain achieved by this route, it is possible that it would have an effect equivalent to that obtained with much higher doses given subcutaneously or intraperitoneally, as was the case in the current study. It is clear that differences in the LH response of photostimulated and photoinhibited animals would not be as marked using such a potent dose (see Fig. 1), whereas the major difference in sensitivity can be revealed at lower concentrations (e.g. compare responses in different photoperiods to 25 and $75 \mathrm{mg} \mathrm{kg}^{-1}$ body weight in Fig. 1). A second difference is that in the study of Urbanski, hamsters were anaesthetized with methoxyflurane vapour so that the jugular vein could be exposed for the i.v. injection. The control LH values from anaesthetized long-day hamsters were less than $50 \%$ of those from long-day hamsters reported in other experiments, so it is possible that basal LH concentrations were partially suppressed by the anaesthesia. Consequently, the NMDA treatment might appear to be more effective in long-day animals because it is stimulating a partially inhibited system.

In general, our observations support the view that the mechanism by which daily NMDA injections counteract the inhibitory effects of short days is by the stimulation of LH secretion (Urbanski, 1990). Although this might initially appear to be an obvious conclusion, there is a large body of evidence that indicates that glutamatergic mechanisms mediate or facilitate the effects of light in entraining circadian rhythmicity, and thus, in generating the daily pattern of melatonin secretion (Meijer \& Rietveld, 1989; Colwell et al., 1990; Ebling et al., 1991a). The daily pattern of melatonin secretion conveys photoperiodic information to the mechanisms controlling GnRH secretion (Bartness \& Goldman, 1989; Hastings, 1991). Thus, all chronic pharmacological manipulations of glutamatergic systems could potentially affect not only the transduction of photoperiodic information via the suprachiasmatic nucleus and thence the pineal gland, but also the expression of the photoperiodic response that depends upon such information but is effected by more distal neural systems controlling GnRH secretion. For example, a recent study has reported that the glutamate antagonist MK801 injected once a day before a nocturnal light pulse blocks the stimulatory effect of this 'skeleton' long day on reproductive function in the Syrian hamster (Colwell et al., 1991). It is argued that the mechanism of action of this antagonist delivered once a day is to block the photic entrainment of a short duration noctural melatonin peak that would otherwise convey a stimulatory long-day signal to the mechanisms controlling GnRH secretion.

The effects of NMDA on LH secretion are probably mediated by stimulation of GnRH secretion. Studies in rats and sheep in which pretreatment with GnRH antagonists block the actions of NMDA on LH release (Gay \& Plant, 1987; Plant et al., 1989; Lincoln \& Wu, 1991), and the observation that infusion of low doses of NMDA directly into the brain elicit $\mathrm{LH}$ secretion in rats (Ondo et al., 1988) and hamsters (Ebling et al., 1991b) both argue against direct induction of LH secretion from the pituitary gland. Moreover, NMDA can elicit GnRH release from hypothalamic explants in vitro (Bourguignon et al., 1989). The current studies also demonstrate the potential for glutamatergic involvement in the control of prolactin secretion, and show that during long days when low doses of NMDA are ineffective in stimulating LH secretion, they suppress prolactin secretion. This inhibitory effect on prolactin secretion in the Syrian hamster is in contrast to the prepubertal rhesus monkey, in which NMDA stimulates prolactin secretion (Gay \& Plant, 1987). In the hamster, it is likely that the effect of NMDA is to stimulate the secretion of dopamine by the tuberoinfundibular dopaminergic neurons, and thereby inhibit the lactotrophs of the anterior pituitary. The presumed effects of systemically administered NMDA upon GnRH and dopamine release are probably mediated via post-synaptic elements of glutamatergic systems located in the 
region of the arcuate nucleus and median eminence of the hypothalamus where the blood-brain barrier, which would exclude polar substances such as NMDA, is incomplete. NMDA would therefore have direct access to neuronal perikarya, synaptic terminals and neurosecretory endings in this region.

Several explanations could account for the reduced response to NMDA seen in long day and photorefractory hamsters. One possibility is that $\mathrm{GnRH}$ secretion induced by NMDA remains constant, but marked changes in pituitary responsiveness to GnRH occur. However, it is unlikely that in long-day hamsters, which have high baseline gonadotrophin secretion relative to short-day hamsters, pituitary sensitivity could be so diminished that a response to additional NMDAinduced GnRH would not be seen. Furthermore, in their study of male sheep, Lincoln \& Wu (1991) demonstrated that changes in the response to NMDA occurred even though pituitary sensitivity to exogenous GnRH challenges did not vary. A second possibility is that hypothalamic GnRH stores are depleted in the sexually active hamster that has by definition a high endogenous rate of GnRH secretion, thus GnRH secretion cannot be induced above the already high level. This also seems unlikely; other pharmacological treatments increase LH secretion in long-day hamsters, for example blockade of endogenous opioid inhibition with naloxone (Roberts et al., 1985; Juss et al., 1991). These responses to naloxone suggest that there is a releasable pool of GnRH in long-day hamsters, and that LH secretion can be stimulated above basal levels in reproductively active hamsters. A third possibility is that feedback by testicular secretions in hamsters maintained in long days might decrease the sensitivity of GnRH secretion to NMDA stimulation. However, removal of potential testicular feedback by castration of long-day hamsters did not reveal a stimulatory effect of NMDA on LH secretion; castration was associated with an inhibitory effect of NMDA upon LH secretion, and a stimulation of LH release after treatment with the NMDA antagonist, MK801. It therefore seems unlikely that the enhanced response to NMDA in short-day hamsters is simply a consequence of reduced serum concentrations of testosterone. However, this experiment has the limitation that as a consequence of removing testicular feedback, basal $\mathrm{LH}$ secretion rises markedly, thus the likelihood of observing a further increase might be diminished. Clearly, further studies are necessary to determine whether responsiveness to NMDA changes in different photoperiods in castrate hamsters bearing a testosterone implant to provide a constant but physiologically active concentration of hormone. The paradoxical inhibitory effect of NMDA in castrates will be considered below.

The fourth explanation for the change in responsiveness to NMDA is that changes in endogenous glutamatergic activation induced by photoperiod dictate the response seen to exogenous agonists. Thus, NMDA might be less effective in stimulating LH secretion in long-day hamsters, in contrast to photoinhibited animals, because endogenous glutamatergic drive is already at a maximum in the former, or because anatomical or functional changes in NMDA receptors have occurred. If the first hypothesis was correct, a decline in LH concentrations in response to a glutamate antagonist might be predicted. No effects of acute treatment with MK801 on $\mathrm{LH}$ secretion were observed in the current study, although the limitations of this experiment, namely the use of only a single dose and the acute period of blockade should be borne in mind. Nevertheless, there are as yet no reports of suppressive effects of NMDA antagonists on tonic LH secretion in intact sexually active mammals. To date, NMDA antagonists have been reported to be effective only in delaying the endogenous activation of gonadotrophin secretion at puberty (Urbanski \& Ojeda, 1990; Veneroni et al., 1990; Wu et al., 1990), or in blocking steroid-induced LH surges (Brann \& Mahesh, 199la, b) and in one study reducing LH secretion in castrate rats (Arslan et al., 1988). With regard to the second possibility, autoradiographic studies indicate that NMDA receptors are present in the hypothalamus, albeit at much lower densities than most other areas of the central nervous system (Monaghan \& Cotman, 1985), and a preliminary report suggests that the density is actually increased in the preoptic area in long-day hamsters at the time when systemic NMDA is less effective in stimulating LH secretion (Urbanski \& Pierce, 1990). NMDA was effective in suppressing prolactin secretion in long-day hamsters, so long days do not induce a general loss 
of response to NMDA-receptor stimulation. Nevertheless, it may be hypothesized that NMDA receptors are not functionally linked to GnRH release in the sexually active state, and thus, endogenous glutamatergic activity is not necessary for the maintenance of reproductive function. If so, it is possible that increased glutamatergic activity might induce transitions in reproductive function, for example at puberty and the onset of reproductive activity in adult seasonal breeders, but maintenance of fertility, once established, is independent of glutamate.

A further explanation for the loss of response to NMDA in the sexually active condition was raised by Lincoln \& Wu (1991), namely that other inhibitory mechanisms are involved, for example opioidergic pathways. Thus, responses to NMDA are gated by such overriding inhibitory systems. This possibility remains to be tested experimentally.

The principal reason for studying NMDA responses in castrate hamsters was to determine whether removal of testicular secretions would permit a stimulatory effect of NMDA to be revealed in long days. The unexpected result that NMDA reduced LH concentrations is complemented by the finding that the NMDA antagonist MK801 increased serum LH in castrates. Thus, the decrease in serum LH induced by NMDA 30 min after injection is unlikely simply to reflect a rebound from a transient increase. As previously noted, the influence of manipulations of glutamatergic systems on the pulsatile pattern of LH secretion has not been examined. It is quite possible that induction of an even higher frequency of $\mathrm{GnRH}$ episodes in the castrate condition might be reflected by a decrease in the pituitary response, and thus, lower mean LH concentrations overall. This phenomenon has been observed in ovariectomized female sheep in which opiate antagonism with naloxone increased LH pulse frequency but decreased mean LH concentrations (Ebling et al., 1989). Conversely, if MK801 had decreased GnRH pulse frequency, an enhanced pituitary response to each pulse might occur. However, more detailed studies in other species of the episodic pattern of $\mathrm{LH}$ release provide further evidence that removal of gonadal steroids influences the response to NMDA. Estienne et al. (1989) reported that NMDA failed to alter significantly LH pulse frequency in chronically castrated male sheep, though a trend towards decreased pulse frequency was evident. Similar results have been obtained from female sheep. Whereas NMDA stimulates LH secretion in the anoestrous season in ovary intact or oestradiol-replaced ovariectomized sheep (Ebling \& Foster, 1990; Estienne et al., 1990; Jansen et al., 1991), no effect in chronically ovariectomized females has been noted in the absence of steroid replacement (Estienne et al., 1990). An inhibitory effect of NMDA on LH in chronically ovariectomized adult rhesus monkeys has also been reported (Reyes et al., 1990), the decrease in LH concentrations in NMDA-treated ovariectomized monkeys being correlated with a rise in cortisol secretion. Moreover, pretreatment with a corticotrophin-releasing factor antiserum, or the opiate receptor antagonist naloxone, prevented the NMDA-induced decrease in LH concentrations in some monkeys (Reyes et al., 1990). It is therefore likely that, in the rhesus monkey at least, the suppressive effects of NMDA on LH secretion in the absence of gonadal steroids may stem indirectly from the activation of both endogenous opioid mechanisms and hypothalamic drive to the adrenal axis.

The finding that NMDA induced LH secretion in hamsters with regressed testes in short days suggests that the ability to synthesize and release GnRH exists in the seasonally inactive state, but that activation of the GnRH secretory system is lacking. Furthermore, the differences in sensitivity and response to NMDA that occur in different reproductive states raise the possibility that changes in endogenous glutamatergic activity might underlie the alteration in reproductive function. Whether such an endogenous mechanism might contribute to the maintenance of the reproductive axis, or only to its initial activation, remains to be determined.

This work was supported by the Medical Research Council UK with a Training Fellowship to FJPE (G84/2235) and a Project Grant to MHH (G8912713N). We thank S. Iversen at Merck, Sharpe and Dohme Neuroscience Research Centre for the gift of MK801, and the NIADDK, A. F. Parlow and F. Talamantes for reagents for radioimmunoassays. 


\section{References}

Arslan, M., Pohl, C.R. \& Plant, T.M. (1988) D,L-2-amino5-phosphonopentanoic acid, a specific $N$-methyl-Daspartic acid receptor antagonist, suppresses pulsatile LH release in the rat. Neuroendocrinology 47, 465-468.

Bartke, A., Goldman, B.D., Bex, F.J., Kelch, R.P., Smith, M.S., Dalterio, S. \& Coherty, P.C. (1980) Effects of prolactin on testicular regression and recrudescence in the golden hamster. Endocrinology 106, 167-172.

Bartness, T.J. \& Goldman, B.D. (1989) Mammalian pineal melatonin: a clock for all seasons. Experientia 45, 939-945.

Bourguignon, J-P., Gerard, A. \& Franchimont, P. (1989) Direct activation of gonadotropin-releasing hormone secretion through different receptors to neuroexcitatory amino acids. Neuroendocrinology 49, 402.408 .

Brann, D.W. \& Mahesh, V.B. (1991a) Endogenous excitatory amino acid regulation of the progesteroneinduced LH and FSH surge in estrogen-primed ovariectomized rats. Neuroendocrinology $53,107-110$.

Brann, D.W. \& Mahesh, V.B. (1991b) Endogenous excitatory amino acid involvement in the preovulatory and steroid-induced surge of gonadotropins in the female rat. Endocrinology 128, 1541-1547.

Colwell, C.S., Ralph, M.R. \& Menaker, M. (1990) Do NMDA receptors mediate the effects of light on circadian behavior? Brain Research 523, 117-120.

Colwell, C.S., Max, M., Hudson, D. \& Menaker, M. (1991) Excitatory amino acid receptors may mediate the effects of light on the reproductive system of the golden hamster. Biology of Reproduction 44, 604-608.

Ebling, F.J.P. \& Foster, D.L. (1990) Seasonal breeding a model for puberty? In Control of the Onset of Puberty III, pp. 253-264. Eds H. A. Delemarre-van de Waal, I. M. Plant, G. P. van Rees \& J. Shoemaker. Elsevier Science Publishers, Amsterdam.

Ebling, F.J.P. \& Lincoln, G.A. (1985) Endogenous opioids and the control of seasonal LH secretion in Soay rams. Journal of Endocrinology 107, 34I-353.

Ebling, F.J.P., Schwartz, M.L. \& Foster, D.L. (1989) Endogenous opioid regulation of pulsatile LH secretion during sexual maturation in female sheep. Endocrinology 125, 369-383.

Ebling, F.J.P., Wood, R.I., Karsch, F.J., Vannerson, L.A., Suttie, J.M., Bucholtz, D.C., Schall, R.E. \& Foster, D.L. (1990) Metabolic interfaces between growth and reproduction: III Central mechanisms controlling LH secretion in the nutritionally growthlimited female lamb. Endocrinology 126, 2719-2727.

Ebling, F.J.P., Maywood, E.S., Staley, K., Humby, T., Hancock, D.C., Waters, C.M., Evan, G.I. \& Hastings, M.H. (1991a) The role of NMDA-type glutamatergic neurotransmission in the photic induction of immediate-early gene expression in the suprachiasmatic nuclei of the Syrian hamster. Journal of Neuroendocrinology 3, 64I-652.

Ebling, F.J.P., Hui, Y., Maywood, E.S. \& Hastings, M.H. (1991b) Photoperiod regulates the response to central glutamatergic stimulation in the male Syrian hamster. Society for Neurosciences Abstracts 17:428 (Abstract 175.12).
Estienne, M.J., Schillo, K.K., Green, M.A., Hileman, S. \& Boling, J.A. (1989) $N$-methyl-D,L-aspartate stimulates growth hormone but not luteinizing hormone secretion in the sheep. Life Sciences 44, 1527-1533.

Estienne, M.J., Schillo, K.K., Hileman, S., Green, M.A. \& Hayes, S.H. (1990) Effect of $N$-methyl-D,L-aspartate on luteinizing hormone secretion in ovariectomized ewes in the absence and presence of estradiol. Biology of Reproduction 42, 126-130.

Gay, V.L. \& Plant, T.M. (1987) $N$-methyl-D,L-aspartate elicits hypothalamic gonadotropin-releasing hormone release in prepubertal male rhesus monkeys (Macaca mulatta). Endocrinology 120, 2289-2296.

Gay, V.L. \& Plant, T.M. (1988) Sustained intermittent release of gonadotropin-releasing hormone in the prepubertal male rhesus monkey induced by $N$-methylD, L-aspartic acid. Neuroendocrinology 48, 147-152.

Hastings, M.H. (1991) Neuroendocrine rhythms. Pharmacology and Therapeutics 50, 35 72.

Hastings, M.H., Maywood, E.S., Ebling, F.J.P., Williams, L.M. \& Titchener, L. (1991) Sites and mechanism of action of melatonin in the photoperiodic control of reproduction. Advances in Pineal Research 5, 147-157.

Hui, Y., Ebling, F.J.P., Maywood, E.S. \& Hastings, M.H. (1991) Short photoperiods increase the responsiveness of LH secretion to NMDA stimulation in the Syrian hamster. Journal of Reproduction and Fertility Abstract Series 7, 25 (Abstract 39).

Jansen, H.T., Khalid, M. \& Jackson, G.L. (1991) Nmethyl-D,L-aspartate induces a transient increase in LH secretion in the seasonally anestrous ewe. Domestic Animal Endocrinology 8, 55-62.

Juss, T.S., Maywood, E.S., Walker, A.P., Herbert, J. \& Hastings, M.H. (1991) The influence of photoperiod on the hypothalamic content of $\beta$-endorphin and the LH responses to naloxone and to steroid withdrawal in the male Syrian hamster. Journal of Neuroendocrinology 3, 461-467.

Lincoln, G.A. \& Wu, F.C.W. (1991) Luteinizing hormone responses to $N$-methyl-D,L-aspartate during a photoperiodically induced reproductive cycle in the ram. Journal of Neuroendocrinology 3, 309-317.

Lopez, F.J., Donosa, A.O. \& Negro-Vilar, A. (1990) Endogenous excitatory amino acid neurotransmission regulates the estradiol-induced LH surge in ovariectomized rats. Endocrinology 126, 1771-1773.

Meijer, J.H. \& Rietveld, W.J. (1989) Neurophysiology of the suprachiasmatic circadian pacemaker in rodents. Physiological Review's 69, 671-707.

Meyer, S.L. \& Goodman, R.L. (1985) Neurotransmitters involved in mediating the steroid-dependent suppression of pulsatile luteinizing hormone secretion in anestrous ewes: effects of receptor antagonists. Endocrinology 116, 205-211.

Monaghan, D.T. \& Cotman, C.W. (1985) Distribution of $N$-methyl-D-aspartate-sensitive $\mathrm{L}-\left[^{3} \mathrm{H}\right]$ glutamate binding sites in rat brain. Journal of Neuroscience 5, 2909-2919.

Ondo, J.G., Wheeler, D.D. \& Dom, R.M. (1988) Hypothalamic site of action for $N$-methyl-D-aspartate (NMDA) on LH secretion. Life Sciences 43, 22832286. 
Plant, T.M., Gay, V.L., Marshall, G.R. \& Arslan, M. (1989) Puberty is triggered by chemical stimulation of the hypothalamus. Proceedings of the National Academy of Sciences USA 86, 2506-2510.

Reyes, A., Luckhaus, J. \& Ferin, M. (1990) Unexpected inhibitory action of $N$-methyl-D, L-aspartate on luteinizing hormone release in adult ovariectomized rhesus monkeys: a role of the hypothalamic adrenal axis. Endocrinology 127, 724-729.

Roberts, A.C., Hastings, M.H., Martensz, N.D. \& Herbert, J. ( 1985) Naloxone-induced secretion of luteinizing hormone in the male Syrian hamster: modulation by photoperiod and gonadal steroids. Journal of Endocrinology 106, 243-248.

Swann, J.M. \& Turek, F.W. (1988) Transfer from long to short days reduces the frequency of pulsatile luteinizing hormone release in intact but not in castrated male golden hamsters. Neuroendocrinology 47, 343-349.

Talamantes, F., Marr, G., DiPinto, G.M.N. \& Stetson, M.H. (1984) Prolactin profiles during oestrous cycle and pregnancy in the hamster as measured by homologous RIA. American Journal of Physiology 247, E126-E129.

Urbanski, H.F. (1990) A role for $N$-methyl-D-aspartate receptors in the control of seasonal breeding. Endocrinology 127, 2223-2228.
Urbanski, H.F. \& Ojeda, S.R. (1987) Activation of luteinizing hormone-releasing hormone release advances the onset of female puberty. Neuroendocrinology 46, 273-276.

Urbanski, H.F. \& Ojeda, S.R. (1990) A role for $N$ methyl-D-aspartate (NMDA) receptors in the control of LH secretion and initiation of female puberty. Endocrinology 126, 1774-1776.

Urbanski, H.F. \& Pierce, M. (1990) Photoperiodic modulation of $N$-methyl-D-aspartate (NMDA) receptor binding in the Syrian hamster. Society for Neuroscience Abstracts 16, 285. Abstract 126.8.

Urbanski, H.F. \& Simpson, S.M. (1982) Photoperiodic suppression of gonadotrophin secretion in castrated male hamsters. Journal of Reproduction and Fertility 66, 299-303.

Veneroni, O., Cocilovo, L., Muller, E.E. \& Cocchi, D. (1990) Delay of puberty and impairment of growth in female rats given a non-competitive antagonist of NMDA receptors. Life Sciences 47, 1253-1260.

Wu, F.C.W., Howe, D.C. \& Naylor, A.M. (1990) Nmethyl-D,L-aspartate receptor antagonism by $\mathrm{D}-2$ amino-5-phosphonovaleric acid delays onset of puberty in the female rat. Journal of Neuroendocrinology 2, 627-631.

Received 5 August 1991 